\title{
A RARE CASE REPORT OF XERODERMA PIGMENTOSUM WITH STRONG FAMILIAL ASSOCIATION
}

\author{
Basavaraj R. Patil Raikod ${ }^{1}$, Niraj Saraf ${ }^{2}$, Sudhanva V. Kinhal ${ }^{3}$
}

\section{HOW TO CITE THIS ARTICLE:}

Basavaraj R. Patil Raikod, Niraj Saraf, Sudhanva V. Kinhal. "A Rare Case Report of Xeroderma Pigmentosum with Strong Familial Association". Journal of Evolution of Medical and Dental Sciences 2014; Vol. 3, Issue 60, November 10; Page: 13473-13476, DOI: 10.14260/jemds/2014/3796

INTRODUCTION: Xeroderma pigmentosum (XP) was first described in 1874 by Hebra and Kaposi. In 1882, Kaposi coined the term xeroderma pigmentosum for the condition, referring to its characteristic dry, pigmented skin. Xeroderma pigmentosum is a rare disorder transmitted in an autosomal recessive manner. It is characterized by photosensitivity, pigmentary changes, premature skin aging, and malignant tumor development. ${ }^{1}$

These manifestations are due to a cellular hypersensitivity to ultraviolet (UV) radiation resulting from a defect in DNA repair. Individuals with this disease develop multiple cutaneous neoplasms at a young age. Two important causes of mortality are metastatic malignant melanoma and squamous cell carcinoma. $\{\operatorname{Re} 24\}$ Patients younger than 20 years have a 1000 -fold increase in the incidence of nonmelanoma skin cancer and melanoma. The mean patient age of skin cancer is 8 years in patients with xeroderma pigmentosum, compared with 60 years in the healthy population. Actinic damage occurs between ages 1 and 2 years.

Here we report a rare presentation of XP with a strong familial association.

CASE REPORT: A 18 year old male patient came to the hospital with history of skin pigmentation since 9 months of age and diminution of vision since 3 years of age. He also complains of difficulty in speaking and walking since past four years. Family history revealed the presence of disease in four out of the six siblings.

On general physical examination, he was poorly built and poorly nourished, stunted and emaciated with multiple hyperpigmented macules present all over the body and multiple ulcers on the oral mucosa. Axillary hair were absent but gonads were normal. Neurological examination revealed intact higher mental functions (MMSE-26/30). There was contracture and tenderness of all the joints. Power in the upper limbs was $4 / 5$ and in lower limbs $3 / 5$, reflexes were exaggerated with extensor plantar response. Cerebellar examination could not be performed.

The patient was instructed to perform proper hygiene of the mouth and rigorous photoprotection of the exposed skin using sunscreen moisturizers, wide-brimmed hat and appropriate clothing. He was also referred for dermatological and ophthalmological evaluation in order to have a multidisciplinary management of the case. 


\section{CASE REPORT}

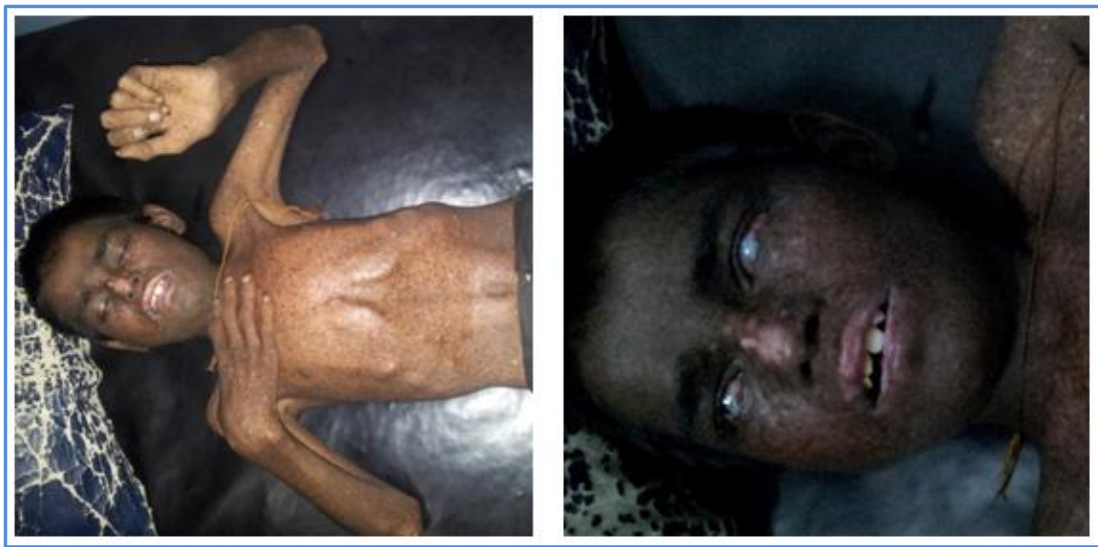

Figure 1

Figure 1: Hyperpigmented macules and papules in the skin face, perioral scars and ophthalmic involvement (bilateral leucomatous corneal opacity).

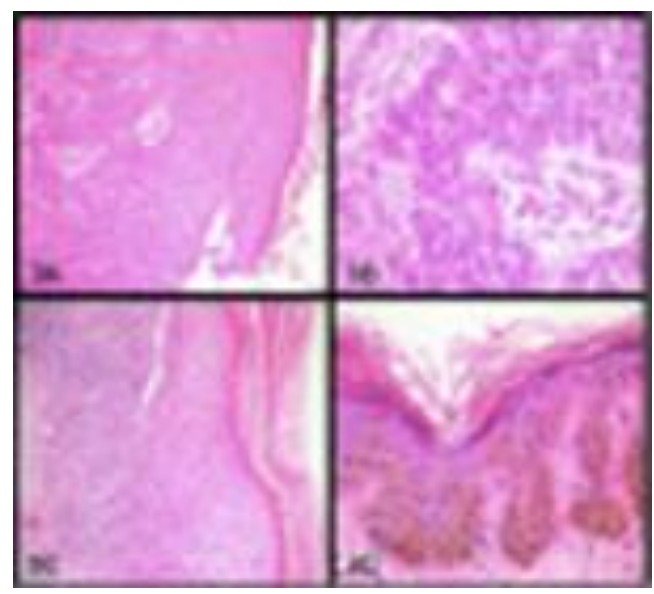

Figure 2

Figure 2: Basal cell carcinoma in facial skin: Blocks of atypical basaloid cells infiltrating the stroma (40x, 200x HE); 3C-Actinic keratosis lichenoides: epithelial hyperplasia and dysplasia associated with infiltrate lichenoid in the dermis (HE 200x);

DISCUSSION: Skin changes are typical features of XP, such as persistent erythema of the skin. In many cases, these symptoms may appear immediately after birth or within the following three years, but it may not develop until late childhood or may not be recognized until adulthood other features of XP are discolorations, weakness and fragility, skin scarring, neurological and ocular disorders. ${ }^{2}$

The differential diagnosis of XP should be performed with two other syndromes caused by mutations of excision repair pathway genes: Cockayne's syndrome (CS) and Trichothiodystrophy (TTD). However, the occurrence of skin cancer associated to high skin sensitivity to UV radiation is commonly observed in XP, but not in CS or TTD cases ${ }^{3}$. The final diagnosis of XP can be confirmed by 
special laboratory tests by examining the DNA damage repair in cells from cultures exposed to ultraviolet radiation. The most common tests are skin biopsy and culture of skin fibroblasts.

De Sanctis Cacchione syndrome has been associated in very few patients XP groups A and D, which represents the most aggressive disease. ${ }^{3}$ In the past, any association of XP and neurological disorders was considered as De Sanctis-Cacchione syndrome. Currently, the diagnostic criteria include severe neurological disease such as microcephaly with progressive mental deterioration, hyporeflexia or areflexia, choreoathetosis, ataxia, spasticity, shortening of Achilles tendon with eventual quadriparesis, markedly retarded growth and immature sexual development.

In addition, patients can present epilepsy, progressive sensorineural deafness and abnormal electroencephalographic findings. ${ }^{3}$ In our case, although the patient had some neurological symptoms, the intensity and the signs described above were not enough to classify this association. Although a detail work up including MRI of the brain and spine along with CPK levels was done, no abnormality could be detected. Genetic analysis was not possible at our centre. A biopsy was performed.

The goal of treatment is to protect the patient from sunlight; to end this regular visit to the dermatologist might be necessary. The use of sunscreens along with sun avoidance methods can minimize UV induced damage. Oral retinoids have been shown to reduce the incidence of skin cancer. This therapy is limited by dose related irreversible calcification of ligaments and tendons (In our patient history of retinoids intake could not be elicited but there were definite contractures along with history of dermatological consultation and unknown drug intake).

The oral manifestations are mainly related to the occurrence of malignant tumors in the lips, tongue and buccal mucosa ${ }^{4}$. In our case there was actinic cheilitis. Actinic cheilitis is a potentially malignant lesion that affects the lower lip of white patients who were frequently exposed to sun. Pain is a consequence of fibrous area that stretches when the patients opens the mouth for feeding, speaking, breathing, and for oral hygiene performance. Therefore, the patient has poor hygiene habits and consequently, a high rate of dental plaque, caries and periodontal disease.

There is no cure for XP. Treatment consists of minimizing exposure to sunlight and regular dermatological care, as well as surgery for recurrent tumors excision. Early diagnosis and extensive sun protection have the potential to prevent skin cancers in XP patients and prolong their life expectancy. Although the management of XP is complicated due to the difficulty in avoiding daily UV exposure, sun protection can be achieved by wearing protective clothing, UV-absorbing sunglasses with side shields and the use of topic sun blocking agents. UV-absorbing films and filters can be placed over windows and fluorescent or halogen lamps.

Self- and dermatological skin examinations to monitor any skin changes and ensure early detection and treatment of skin cancers should be regularly performed. Also, an ophthalmologist must be involved since the beginning of the management of these patients ${ }^{5}$ Eye care consists of sunglasses, artificial tears, steroid drops, and bland ointment at night. These are essential components of a prevention program. Patients should be followed up every 3 months

Genetic counseling is also an important component of XP patient management, especially in a family that has an affected child and is considering having more children. XP patients have 1,000 times more chances of developing early skin cancer including squamous cell carcinoma, basal cell carcinoma and melanoma; less frequently. ${ }^{6}$ Clinical examination carried out regularly by the dentist is mandatory for the detection of premalignant or malignant lesions. 
Furthermore, it is necessary to establish protocols for prophylaxis and topical fluoride application, as well as the use of chlorhexidine digluconate $0.12 \%$, aiming the homeostasis of the oral environment.

The use of mouthwashes with high alcohol concentration should be avoided because there is an increased risk of developing oral cancer in these. Finally, the main oral manifestations of XP are actinic cheilitis, basal cell and squamous cell carcinomas. In addition, the presence of scars and lip repair surgery sequels are commonly observed, resulting in difficult oral care and hygiene.

\section{REFERENCES:}

1. English JS, Swerdlow AJ. The risk of malignant melanoma, internal malignancy and mortality in xeroderma pigmentosum patients. Br J Dermatol. Oct 1987; 117 (4): 457-61. (Medline)

2. De Silva BD, Nawroz I, Doherty VR. Angiosarcoma of the head and neck associated with xeroderma pigmentosum variant. Br J Dermatol. 1999; 141: 166-7. [PubMed]

3. Woods CG. DNA repair disorders. Arch Dis Child. 1998; 78: 178-84. [PMC free article] [PubMed]

4. Goyal JL, Rao VA, Srinivasan R, Agrawal K. Oculocutaneous manifestations in xeroderma pigmentosa.Br J Ophthalmol. 1994; 78: 295-7. [PMC free article] [PubMed]

5. Robbins JH, Kraemer KH, Lutzner MA, Fest off BW, Coon HG. Xeroderma pigmentosum: an inherited disease with sun-sensitivity, multiple cutaneous neoplasms, and abnormal DNA repair. Annals Internal Med.1974; 80: 221-48. [PubMed]

6. Hirai Y, Kodama Y, Moriwaki S, Noda A, Cullings HM, Macphee DG. Heterozygous individuals bearing a founder mutation in the XPA DNA repair gene comprise nearly $1 \%$ of the Japanese population. Mutat Res. 2006; 601: 171-8. [PubMed]

\section{AUTHORS:}

1. Basavaraj R. Patil Raikod

2. Niraj Saraf

3. Sudhanva V. Kinhal

\section{PARTICULARS OF CONTRIBUTORS:}

1. Associate Professor, Department of Medicine, MRMC, Gulbarga.

2. Post Graduate, Department of Medicine, MRMC, Gulbarga.

3. Post Graduate, Department of Medicine, MRMC, Gulbarga.

\section{NAME ADDRESS EMAIL ID OF THE} CORRESPONDING AUTHOR:

Dr. Niraj Saraf,

Flat No. F12, $3^{\text {rd }}$ Floor,

Gulbarga Residency,

RTO Cross, Behind Vatsalya Hospital,

Gulbarga-585105,

Karnataka.

Email: niraj_saraf@yahoo.com

Date of Submission: 27/10/2014.

Date of Peer Review: 28/10/2014.

Date of Acceptance: 05/11/2014.

Date of Publishing: 10/11/2014. 